\title{
Awareness of Oral Cancer and OPMDs among Patients Attending the University Dental Hospital, Peradeniya, Sri Lanka
}

\author{
E. A. Shanika D. Somathunga ${ }^{1}$, D. M. Sithara H. Dissanayaka ${ }^{1}$, D. R. Dilini L. \\ Ratnayake $^{2}$, Ruwan D. Jayasinghe ${ }^{1}$
}

${ }^{1}$ Faculty of Dental Sciences, University of Peradeniya, Sri Lanka. ${ }^{2}$ Ministry of Heath, Sri Lanka.

\begin{abstract}
Objective: To assess awareness of oral cancer and OPMDs among patients attending for dental treatment at the University Dental Hospital, Peradeniya. Methods and materials: A self-administered questionnaire was used to collect information from 500 randomly selected outpatients attended the University Dental Hospital, Peradeniya, Sri Lanka. The questionnaire included questions to ascertain information on socio-demographic parameters, awareness of oral cancer and OPMDs, habits of betel chewing, smoking and alcohol consumption. Results: $43.2 \%$ of the respondents were satisfactorily aware of the possibility of occurrence of oral cancer and OPMDs. From all the individuals who were participated to this questionnaire, $16(3.2 \%)$ of individuals have a habit of betel chewing, $4.2 \%$ of individuals have a habit of smoking and $8.3 \%$ of individuals have a habit of alcohol consumption, respectively while having a satisfactory awareness about oral cancer and OPMDs. Conclusions: This survey revealed that most of the patients attending the hospital were not in a satisfied level of awareness about oral cancer and OPMDs. Knowledge about the causal relationships with betel chewing was low compared to tobacco smoking and alcohol consumption.
\end{abstract}

Keywords: Awareness- oral cancer- OPMDs- betel chewing- tobacco

Asian Pac J Cancer Care, 6 (1), 47-51

\section{Introduction}

Oral cancer (OCA) poses a huge challenge to the wellbeing of people worldwide, particularly across South Asia. Oral cancer (OCA) is a malignant neoplasm of lip, tongue and mouth. Taken together, these cancers were estimated to affect 354,864 people worldwide in 2018, with 177,384 deaths [1]. Fifty-six per cent of the world's oral and pharyngeal cancer burden (excluding nasopharyngeal carcinoma which has different aetiology and biology) is from Asia where overall incidence of oral cancer for men was estimated at 14.8 per 100,000 population per annum in 2018 [1]. Oral cancer is the most common cancer among men in Sri Lanka, eighth amongst women, and second overall [2-3]. Oral cancer accounts for nearly $10 \%$ of reported cancers with the highest mortality rates of all cancers in Sri Lanka [3]. Yet oral cancer is
Submission Date: 11/23/2020Ａcceptance Date: 02/09/2021

\footnotetext{
Corresponding Author:

Dr. Ruwan D. Jayasinghe

Department of Oral Medicine and Periodontology, Faculty of Dental Sciences, University of Peradeniya, Sri Lanka

Email: ruwanja@dental.pdn.ac.lk
} 
OPMD is estimated to range between 1 and 5\% [9-10]. Mello et al [10] estimated the prevalence of OPMDs to be $10.54 \%$ for Asian populations but these findings vary by type of OPMD: The prevalence of oral submucous fibrosis (OSMF) is estimated to be $4.96 \%$, Oral Leukoplakia (OL) $4.11 \%$, and $0.17 \%$ prevalence for erythroplakia [10]. In Sri Lanka, the prevalence of OL and of OSF was reported as $2 \%$ and $1.5 \%$ respectively among the $35-44$ and $65+$ age groups [11]. In a high risk population of tea estate labourers of Sri Lanka, the prevalence for OPMD was reported as $6.7 \%$ with $4.61 \%$ prevalence for $\mathrm{OL}$ and $1.64 \%$ for OSF [12]. Such wide geographical variations are due to life styles specific to the country or the region. Betel quid chewing with or without tobacco, chewing of areca nut, either traditional or commercially prepared forms are major contributory factors for oral cancer and OPMD in the South Asian region.

As management of oral cancer in Sri Lanka is costly [13] and seriously affects quality of life primary prevention and early detection of OPMDs is essential if we are to reduce the incidence and to reduce the impact of this dreadful disease on population health and healthcare costs. The stage of diagnosis is important for survival. Oral cancers have a high likelihood of cure when detected at an early stage [14]. The lack of awareness on oral cancer and oral potentially malignant disorders (OPMD) and their risk factors among public as well as among health care professionals [15] is an important reason for late detection of these conditions [16].

Previous studies have demonstrated that the knowledge on oral cancer among people s better compared to OPMD [17-18-19]. Their knowledge on risk factors varies. In some studies there is an overall lack of awareness on risk factors [19] whereas some other have shown a low awareness on smoking and alcohol compared to betel chewing [17-18].

Education programs aiming at minimizing the oral cancer risk has to be developed using the existing knowledge and the gaps in the knowledge. Multiple educational programs are conducted in Sri Lanka by different organizations. Therefore, the primary aim of this study was to assess the awareness and knowledge of oral cancers and oral potentially malignant disorders and their risk factors among the patients attending the university dental hospital, Peradeniya, Sri Lanka.

\section{Materials and Methods}

A hospital based cross sectional study was conducted at the Out Patients Department (OPD) of the University Dental Hospital, Peradeniya, Sri Lanka. Randomly selected 500 OPD attendees were recruited to the study. Self-administered pre tested questionnaire was given to the study participants while they were waiting for treatment. The self-administered questionnaire includes questions to ascertain information on socio-demographic parameters, awareness of oral cancer and OPMDs, habits of betel chewing, smoking and alcohol consumption. Information sheet with necessary details was provided to the participants and informed consent was obtained from all participants prior to the administration of the questionnaire. Ethics approval was obtained from the Ethics Review Committee of the Faculty of Dental Sciences, University of Peradeniya, Sri Lanka. Data were analyzed using SPSS version 21 and chi-squared test was applied to compare groups.

\section{Results}

The study population consisted of 275 females and 225 males with an age range of 14-86 years and an average age of 36 (Table 1). Most of the participants had completed their education up to secondary education (71\%) whereas only $3 \%$ had education up to primary education. Socio-demographic data of the study participants are summarized in the Table 1.

Level of awareness was considered satisfactory when an individual obtained a score of $50 \%$ or more. Accordingly, forty six percent of the respondents had satisfactory level of awareness and the level of awareness was significantly associated with the level of education ( $x 2=14.296, p=0.001)$ of the study participants. Binomial logistic regression was performed to ascertain the adjusted effects of age, gender, ethnicity, occupation and level of education on the likelihood that study participants possessed a satisfactory level of awareness. The logistic regression model was statistically significant $(x 2=29.46$, $\mathrm{P}=0.003$ ). However the model explained only $7.6 \%$ (Nagelkerke R2) of the variance in awareness level and correctly classified $60.4 \%$ of cases who possessed a satisfactory and non-satisfactory level of awareness. According to the model those who have obtained their education up to G.C.E. O/L or G.C.E. A/L (secondary education $)(\mathrm{OR}=5.41,95 \% \mathrm{CI}=1.46-19.98, \mathrm{p}=0.01)$ and primary education possessed a higher level of awareness $(\mathrm{OR}=1.82,95 \% \mathrm{CI}=1.14-2.28, \mathrm{p}=0.012)$ when compared with the individuals who have possessed their tertiary education. Most of them have obtained the awareness from TV/radio, newspapers, posters or banners whereas only around $10 \%$ have received it from healthcare workers

Table 1. Distribution of Respondents According to the Socio-demographic Data

\begin{tabular}{lcc}
\hline & Number & Percentage (\%) \\
\hline Gender & & \\
Male & 225 & 45 \\
Female & 275 & 55 \\
Age & & \\
$14-24$ & 139 & 27.8 \\
$25-34$ & 95 & 19 \\
$35-44$ & 93 & 18.6 \\
$45-54$ & 91 & 18.2 \\
$55-64$ & 45 & 9 \\
Above 64 & 37 & 7.4 \\
Ethnicity & & \\
Major ethnic group & 428 & 85.6 \\
Minor ethnic groups & 72 & 14.4 \\
\hline
\end{tabular}


Table 2. Sources of Awareness about Oral Cancer and OPMDs

\begin{tabular}{lcc}
\hline Sources of awareness about Oral Cancer and OPMD & Frequency & Percentage (\%) \\
\hline No response & 171 & 34.2 \\
From Family Members & 8 & 1.6 \\
From Friends & 8 & 1.6 \\
From a Physician & 24 & 4.8 \\
From a Dental Surgeon & 29 & 5.8 \\
From Midwife & 9 & 1.8 \\
By Newspaper & 22 & 4.4 \\
By T.V./Radio & 71 & 14.2 \\
By Other ways (poster, banner) & 22 & 4.4 \\
Two or More responses & 136 & 27.2 \\
Total & 500 & 100 \\
\hline
\end{tabular}

Table 3. Association between Habits and Level of Awareness on Oral Cancer and OPMD

\begin{tabular}{lccc}
\hline Major risk factors & $\mathrm{X} 2$ & $\mathrm{df}$ & $\mathrm{P}$ value \\
\hline Betel Chewing & 6.916 & 1 & 0.008 \\
Smoking & 0.824 & 1 & 0.364 \\
Alcohol & 1.447 & 1 & 0.229 \\
\hline
\end{tabular}

(Table 2). Some questions were directed to ascertain the awareness about the link between oral cancer and OPMDs with various habits including betel chewing $16(3.2 \%)$, tobacco smoking $4.2 \%$ and alcohol consumption $8.3 \%$. Out of 500 subjects $2.8 \%$ have used betel quid with all ingredients (betel leaf, areca nut, tobacco and lime) while $2.6 \%$ chewed without tobacco. Furthermore habit of betel chewing was significantly associated with the level of awareness on oral cancer and OPMD $(\mathrm{P}=0.008)$ (Table 3).

\section{Discussion}

Ministry of Health of Sri Lanka, Faculty of Dental Sciences of the University of Peradeniya, Sri Lanka and many other governmental and non-governmental organizations and institutions conduct multiple programs using multiple methods of communication to educate the people of Sri Lanka on oral cancer prevention especially on the prevention of risk habits. Yet, oral cancer is a major public health problem in Sri Lanka [3]. Even though there is a reduction in smoking, number of people who use betel quid is increasing [20].

Oral cancer is usually preceded by an oral potentially malignant disorder (OPMD), especially in the south and south East Asia. Global prevalence of OPMD is estimated to be $1-5 \%$ (Napier and Speight, 2008, Mello et al., 2018). Prevalence of OPMD is higher in South \& South East Asia [21-22]. In Sri Lanka, the prevalence of oral leukoplakia (OL) and oral sub mucous fibrosis (OSF) was reported as $2 \%$ and $1.5 \%$ respectively among the $35-44$ and $65+$ age groups [11].

Even though oral cancer occurs in an anatomical site which is visible to both the affected individual and to an examining clinician, most patients with an OCA report late to the hospitals, with advanced disease. Every year around 2500 new cases of OCA are diagnosed in Sri Lanka where almost all patients go on to receive treatment from state sector hospitals. Sri Lanka is a country with $100 \%$ free health services. According to the National Cancer Incidence data year 2011, more than $76.5 \%$ of the total reported oral cancer cases were in UICC/AJCC stages 111 and 1V [3]. This is one of the most important poor prognostic marker of oral cavity cancers. Lack of awareness about OPMD and oral cancer is one reasons for late diagnosis. Therefore early identification of oral cavity cancer and OPMD by health care professionals and by people themselves will be a great advantage in the management of oral cavity cancer.

According to the findings of current survey, only $43.2 \%$ of participants had a satisfactory level of awareness on oral cancer and OPMDs. Knowledge on oral cancer was much better than that of the OPMD. Oral cancer/ OPMD awareness among people varies considerably in literature. Some have shown a poor knowledge like ours [18] whereas some other have shown a better knowledge [23-24]. A similar study conducted in the same hospital 15 years ago, awareness on oral cancer was $95 \%$ whereas for precancer it was $45 \%$ highlighting a significant reduction in the level of awareness among the patients attending to the Dental Hospital, Peradeniya [17]. Management of oral cavity cancer is not an easy task, most of the time leading to poor prognosis, poor quality of life of the patients and are costly whereas the management of OPMD is much easier, economical with better outcomes [13]. Timely diagnosis of OPMD and proper management can help in preventing malignant transformation. In this context it is important to note that more than $55 \%$ of the respondents were without a satisfactory level of knowledge on OPMDs and oral cancers and awareness on oral cancer/ OPMD has reduced over the years. This information is an eye opener 
to the health care professional especially public health specialists of this country and points to the dire need for educational programs to enlighten the public about this dreadful disease. Surprisingly we observed a lower level of awareness in people with higher level of education.

Even though the manufacturing and selling of smokeless tobacco is banned in Sri Lanka, still betel quid chewing with smokeless tobacco and areca nut is a very common habit. Many activities using different approaches and different groups have been tried in smokeless tobacco cessation [25] but it is difficult task due to its relationship with social, religious and cultural practices in Sri Lanka. Findings of current survey revealed that the knowledge about the causal relationship with betel chewing was low compared to tobacco smoking and alcohol consumption. But the previous hospital-based study conducted in Sri Lanka found, awareness of the causal relationship of tobacco in the betel quid and occurrence of oral cancer was high compared to tobacco smoking and alcohol consumption [17] demonstrating a declining awareness among people.

Mass media has been identified as an effective tool in educating the people regarding oral cancer and OPMD [26]. There had been many mass media programs organized by various institutions aiming public health education including oral cancer prevention is Sri Lanka. This survey showed that the mass media play a pivotal role in educating the public about oral cancer. Since oral cancer and OPMDs are commonly found in socially and economically deprived strata of the population, it is doubtful whether modes of mass media are readily accessible to the underprivileged groups. The public should be educated and positively encouraged to participate in educational programs on cancer prevention with the hope of minimizing the incidence of this dreadful disease in Sri Lanka. Only a small group of participants have received awareness through dental surgeons/medical officers which has been noted in some other studies as well [23-24]. Health care professionals have a duty and a responsibility in providing health education to their patients. Therefore health care professionals must take an active role in educating the people on oral cancer/ OPMDs.

Although the present study was a hospital-based survey in an urban area, findings of the study revealed some important aspects of the awareness of oral cancer and OPMDs and their risk factors. It demonstrate that the awareness in not adequate and more importantly awareness on OPMD/ Oral cancer as well as risk factors has declined over period of 15 years compared to a similar study. Findings of our study revealed that only a small percentage of participants had received their knowledge on OPMD/Oral Cancer from medical officers or dental surgeons. Major limitation of our study is that it was a hospital based study therefore subjects that we have included are biased and may have better awareness than the people who do not come in to hospitals. Most of the patients coming to this hospital are from urban areas. Most of our patients are either young or middle aged. Therefore it may not be appropriate to generalize the findings hence a well-designed population-based study with a larger sample is need to see the awareness in the population.

\section{Recommendations}

Within those limitations following recommendations can be made from the findings of this study. As the study show a relatively low awareness, it is important to improve the public awareness on OPMD/ Oral cancer and their risk factors. Existing awareness programs need to be reassessed and well-structured, socially and culturally acceptable educational programs should be designed and carried out in the society. Health care professionals should be educated and motivated to engage in patient education regarding the OPMD and oral cancer prevention.

\section{References}

1. Ferlay JEM, Lam F, Colombet M, Mery L, Piñeros M, Znaor A, Soerjomataram I, Bray F. Global Cancer Observatory: Cancer Today. year 2018. Lyon, France: International Agency for Research on Cancer. Available from: https:// gco.iarc.fr/today..

2. National Cancer Control Programme, Minstry of Health, Nutrition \& Indigeneous Medicine, Sri Lanka. Cancer Incidence Data: Sri Lanka Year 2011. Colombo: NCCP. 13th Publication ..

3. National Cancer Control Programme, Minstry of Health, Nutrition \& Indigeneous Medicine, Sri Lanka - 2014, 2014. Cancer Incidence Data Sri Lanka 2014. Www.Nccp.Health. Gov.Lk/Index.Php/Publications/Cancer-Registries..

4. van der Waal I. Potentially malignant disorders of the oral and oropharyngeal mucosa; terminology, classification and present concepts of management. Oral Oncology. 2009 04;45(4-5):317-323. https://doi.org/10.1016/j. oraloncology.2008.05.016

5. Warnakulasuriya S, Ariyawardana A. Malignant transformation of oral leukoplakia: a systematic review of observational studies. Journal of Oral Pathology \& Medicine. 201507 20;45(3):155-166. https://doi.org/10.1111/jop.12339

6. Farah CS, Jessri M, Bennett NC, Dalley AJ, Shearston KD, Fox SA. Exome sequencing of oral leukoplakia and oral squamous cell carcinoma implicates DNA damage repair gene defects in malignant transformation. Oral Oncology. 2019 09;96:42-50. https://doi.org/10.1016/j. oraloncology.2019.07.005

7. Shearston K, Fateh B, Tai S, Hove D, Farah CS. Malignant transformation rate of oral leukoplakia in an Australian population. Journal of Oral Pathology \& Medicine. 2019 06 21;48(7):530-537. https://doi.org/10.1111/jop.12899

8. Shearston K, Fateh B, Tai S, Hove D, Farah CS. Oral lichenoid dysplasia and not oral lichen planus undergoes malignant transformation at high rates. Journal of Oral Pathology \& Medicine. 201906 22;48(7):538-545. https:// doi.org/10.1111/jop.12904

9. Napier SS, Speight PM. Natural history of potentially malignant oral lesions and conditions: an overview of the literature. Journal of Oral Pathology \& Medicine. 200707 05;37(1):1-10. https://doi.org/10.1111/j.16000714.2007.00579.x

10. Mello FW, Miguel AFP, Dutra KL, Porporatti AL, Warnakulasuriya S, Guerra ENS, Rivero ERC. Prevalence of oral potentially malignant disorders: A systematic review and meta-analysis. Journal of Oral Pathology \& Medicine. 201806 06;47(7):633-640. https://doi.org/10.1111/ 
jop. 12726

11. Ministry of Health Sri Lanka , -. 2019. National Oral Health Survey, Sri Lanka (2015/2016), Colombo: Ministry of Health, Nutrition and Indigenous Medicine (Sri Lanka); 2018. Available at http://www.moh.gov.lk..

12. Ariyawardana A, Sitheeque MAM, Ranasinghe AW, Perera I, Tilakaratne WM, Amaratunga EAPD, Yang Y, Warnakulasuriya S. Prevalence of oral cancer and pre-cancer and associated risk factors among tea estate workers in the central Sri Lanka. Journal of Oral Pathology \& Medicine. 200708 01;36(10):581-587. https://doi.org/10.1111/j.16000714.2007.00583.x

13. Amarasinghe $\mathrm{H}$, Jayasinghe $\mathrm{RD}$, Dharmagunawardene D, Attygalla M, Scuffham PA, Johnson N, Kularatna S. Economic burden of managing oral cancer patients in Sri Lanka: a cross-sectional hospital -based costing study. BMJ Open. 2019;9:e027661.

14. Le Campion ACOV, Ribeiro CMB, Luiz RR, da Silva Júnior FF, Barros HCS, dos Santos KDCB, Ferreira SJ, Gonçalves LS, Ferreira SMS. Low Survival Rates of Oral and Oropharyngeal Squamous Cell Carcinoma. International Journal of Dentistry. 2017;2017:1-7. https:// doi.org/10.1155/2017/5815493

15. Jayasinghe RD, Sherminie LPG, Amarasinghe H, Sitheeque MA. Level of awareness of oral cancer and oral potentially malignant disorders among medical and dental undergraduates. Ceylon Medical Journal. 201606 23;61(2):77. https://doi.org/10.4038/cmj.v61i2.8289

16. Amarasinghe HK, Usgodaarachchi US, Johnson NW, Lalloo $\mathrm{R}$, Warnakulasuriya S. Public awareness of oral cancer, of oral potentially malignant disorders and of their risk factors in some rural populations in Sri Lanka. Community Dentistry and Oral Epidemiology. 201008 23;38(6):540-548. https:// doi.org/10.1111/j.1600-0528.2010.00566.x

17. Ariyawardana A, Vithanaarachchi N. Awareness of Oral Cancer and Precancer among Patients Attending a Hospital in Sri Lanka. Asian Pacific Journal of Cancer Prevention. 2005;6:58-61.

18. Formosa Joseph, Jenner Rachel, Nguyen-Thi My-Duyen , Stephens Caitlin, Wilson Corey, Ariyawardana Anura. Awareness and Knowledge of Oral Cancer and Potentially Malignant Oral Disorders among Dental Patients in Far North Queensland, Australia. Asian Pacific Journal of Cancer Prevention. 2015;16(10):4429-34.

19. Shivakumar K, Kadashetti V, Choudhary M, Patil S, Gawnde $\mathrm{M}$. Awareness and knowledge of tobacco associated risk of development of oral cancer and oral potentially malignant disorders among patients visiting a dental college. Journal of Family Medicine and Primary Care. 2020;9(5):2244. https:// doi.org/10.4103/jfmpc.jfmpc_181_20

20. www.searo.who.int/tobacco/documents..

21. Chung C, Yang Y, Wang T, Shieh T, Warnakulasuriya S. Oral precancerous disorders associated with areca quid chewing, smoking, and alcohol drinking in southern Taiwan. Journal of Oral Pathology and Medicine. 2005 09;34(8):460-466. https://doi.org/10.1111/j.1600-0714.2005.00332.x

22. Thomas SJ, Harris R, Ness AR, Taulo J, Maclennan R, Howes N, Bain CJ. Betel quid not containing tobacco and oral leukoplakia: A report on a cross-sectional study in Papua New Guinea and a meta-analysis of current evidence. International Journal of Cancer. 2008 Oct 15;123(8):18711876. https://doi.org/10.1002/ijc.23739

23. Prado N, Bonan R, Leonel A, Castro U, Carvalho E, Silveira F, Perez D. Awareness on oral cancer among patients attending dental school clinics in Brazil. Medicina Oral Patología Oral y Cirugia Bucal. 2020;:e89-e95. https://doi. org/10.4317/medoral.23207

24. Villa A, Kreimer AR, Pasi M, Polimeni A, Cicciù D, Strohmenger L, Gherlone E, Abati S. Oral Cancer Knowledge: A Survey Administered to Patients in Dental Departments at Large Italian Hospitals. Journal of Cancer Education. 201101 05;26(3):505-509. https://doi. org/10.1007/s13187-010-0189-4

25. Hettiarachchi P, Jayasooriya P, Amarasinghe H, Siriwardena B, Wijerathne D, Kithalawa arachchi S, Tilakaratne W, Jayasinghe R. Knowledge and Attitudes of Nursing Students Towards Smokeless Tobacco and Areca Nut Control in Central Province of Sri Lanka. Asian Pacific Journal of Cancer Care. 202008 15;5(3):133-138. https://doi. org/10.31557/apjcc.2020.5.3.133-138

26. Shrestha A, Rimal J. Effectiveness of a Mass Media Campaign on Oral Carcinogens and Their Effects on the Oral Cavity. Asian Pacific Journal of Cancer Prevention. 2018 03;19(3). https://doi.org/10.22034/APJCP.2018.19.3.819

\section{c) (i) 8}

This work is licensed under a Creative Commons AttributionNon Commercial 4.0 International License. 